\title{
Differential Expression of Rac-1, CXCR4 and CCR5 on CD4 T-Cells at Different Stages of HIV-1 Disease Relate To Its Progression in Therapy Naive Individuals
}

\author{
Jaideep S Toor ${ }^{1,3}$, Aman Sharma ${ }^{2}$, Sukhdev S Kamboj ${ }^{3}$ and Sunil K Arora ${ }^{1 *}$ \\ ${ }^{1}$ Department of Immunopathology, Postgraduate Institute of Medical Education \& Research, Chandigarh, India \\ ${ }^{2}$ Departments Internal Medicine, Postgraduate Institute of Medical Education \& Research, Chandigarh, India \\ ${ }^{3}$ Molecular Biology and Biochemistry, Guru Nanak Dev University, Amritsar- Punjab, India
}

\begin{abstract}
Background: HIV-1 uses different co-receptors (CCR5/CXCR4) at different stages of disease to enter target cells. Any information in understanding this mechanism has important implication on both, the rate of disease progression and our understanding of the immunopathogenesis of this disease.

Methods: This cross-sectional study involved 67 treatment-naïve HIV-1 infected individuals. The expression of CCR5 and CXCR4 on T-cell subsets was evaluated in the peripheral blood of patients at different stages of HIV disease, active pulmonary tuberculosis (PTB), HIV/PTB co-infection and healthy controls, to assess their possible role or association with change in Treg frequency during the disease progression. Furthermore, we investigated the impact of Rac1 expression in relation to functionally active CXCR4 and NF-KB expression.

Results: Significantly higher CCR5 expression on CD4+CD25 high Treg cells in HIV-1 subjects in early stage of the disease correlated well with initial decrease in Treg frequency. On the contrary, higher CXCR4 expression on CD4+CD25 low/negative T-cells (non-Treg cells) in advanced stage of disease explained the shift to X4 type with faster progression to AIDS. This shift is further supported by initial significant decrease in Rac1 expression in early disease followed by returning to normal expression with disease progression. Interestingly, PTB co-infection correlated significantly with increase in CCR5 expression on Treg population only, at the same time favoring increase in CXCR4 expression on CD4+CD25 $5^{\text {low/negative }}$ subset.

Conclusion: The study indicates novel inter-relationships of co-receptor expression and their regulatory genes in therapy naïve individuals and how the virus manipulates the host machinery to its advantage. The Rac- 1 seems to regulate not only the functional conformation of CXCR4, but also the expression of both FoxP3 and NF-KB genes there by affecting the disease progression in HIV subjects. These findings need further attention to look at their clinical implication and disease outcome in a larger study.
\end{abstract}

Keywords: HIV-TB co-infection; CCR5/CXCR4 co-receptors; HIV disease progression; Co-receptor utilization; T-regulatory cells

\section{Introduction}

Human Immunodeficiency virus, HIV-1 initiates infection via viral envelope (Env) glycoprotein gp120 interacting with cell surface CD4, followed by its association with a co-receptor that triggers the fusion of viral and host-cell membranes. Two chemokine receptors, CCR5 and CXCR4 are the predominantly known co-receptors for HIV-1 in vivo. All HIV-1 strains are classified phenotypically as R5 (Macrophage tropic), X4 (T-cell tropic), or R5X4 (dual tropic i.e. both M-tropic and T-tropic) depending on whether they preferentially utilize cysteinecysteine receptor 5 (CCR5) or cysteine-X-cysteine receptor 4 (CXCR4) or mixed [1]. This inter-conversion of tropism requires only a small number of changes in the Env V3 region. In early stage of HIV infection, only about $15 \%$ are dual/mixed tropic and is dominated by CCR5 tropism $[2,3]$. While in later stages of the disease, dual/mixed or pure CXCR4 tropism reaches up to $60 \%$ [4], and is highest in patients with $\mathrm{CD} 4 \leq 200$ cells $/ \mu \mathrm{l}[5,6]$.This may vary with the prevalence of HIV-1 subtype in a region. Why there is selective advantage of CCR5 tropic viruses in establishing HIV-1 infection, switching over to CXCR4 utilization in the advanced stage of disease, is not clearly understood yet. This tropism switch has been associated with rapid disease progression and poor clinical prognosis [7-9]. Besides preferential CXCR4-utilizing virus, there may be other factors also playing crucial role in faster disease progression and needs a closer look. It has earlier been indicated that Rac1, a small $(\sim 21 \mathrm{kDa})$ signaling $\mathrm{G}$ protein a member of the $\mathrm{Rac}$ subfamily of the Rho family of GTPases, is important to maintain the functional conformation of CXCR4 receptor [10], and could be one of the candidate molecules that could possibly play an important role in preferential co-receptor utilization by the virus.

Normal cell functioning of host is altered by invading viral proteins to the benefit of the virus [11]. There have been constant efforts to understand these interactions between viral and cellular gene products which together determine the host's susceptibility to infection and disease progression in HIV-1 infection [12]. Working on few such molecules for their behavior in HIV-1 disease progression and $M$. tuberculosis co-infection, we have tried to analyze the role of HIV-1 co-receptors, CCR5 and CXCR4, variant 2 (shorter splice variant) of

*Corresponding author: Sunil K.Arora, Professor, Department of Immunopathology, PGIMER, Chandigarh-160012, India, Tel: +91-172-2755192; Fax: +91-172 2744401; E-mail: skarora_in@yahoo.com

Received March 13, 2013; Accepted April 29, 2013; Published May 03, 2013

Citation: Toor JS, Sharma A, Kamboj SS, Arora SK (2013) Differential Expression of Rac-1, CXCR4 and CCR5 on CD4 T-Cells at Different Stages of HIV-1 Disease Relate To Its Progression in Therapy Naïve Individuals. J AIDS Clin Res 4: 207. doi:10.4172/2155-6113.1000207

Copyright: (c) 2013 Toor JS, et al. This is an open-access article distributed under the terms of the Creative Commons Attribution License, which permits unrestricted use, distribution, and reproduction in any medium, provided the original author and source are credited. 
CXCR4, Rac1 (which is required to maintain CXCR4 in the responsive conformation) [10], NF- $\mathrm{B}$ which has high affinity binding sight on long terminal repeat (LTR) enhancer region of HIV-1 and regulates HIV replication [13-16], and FoxP3 which enhances HIV-1 gene expression by modulating NF- $\kappa B$ occupancy at the LTR in human T-cells line [17].

\section{Materials and Methods}

\section{Patients and controls}

The study was conducted on different cohorts of individuals including $27 \mathrm{HIV}-1$ infected patients, 12 Mycobacterium tuberculosis (Mtb) infected patients (PTB), 8 HIV-1/Mtb co-infected patients (HIVPTB), and 20 healthy controls (HC). HIV-1 infected patients confirmed by the blood sample being reactive by three rapid tests, as per National AIDS Control Organization (NACO) guidelines were enrolled from the Integrated Counselling and Testing Centre (ICTC) in the Department of Immunopathology, PGIMER, and Chandigarh, India. At the time of recruitment, the patients were interviewed by a counsellor to obtain informed consent and ascertain therapy naïve status. The status of disease was assessed by absolute CD4 cell count by flow cytometry using BD Tritest ${ }^{\mathrm{m}}$ containing antibody conjugates CD3-FITC/ CD4-PE/CD45-PerCP with BD Trucount ${ }^{\mathrm{m} s}$ tubes (BD Biosciences, San Jose, USA). PTB and HIV-PTB patients confirmed positive for Mycobacterium tuberculosis by chest x-ray, sputum smear positivity and TB-PCR were recruited from DOTS centre, in our hospital.The study was approved by the Institutional Ethics Committee (IEC) of Postgraduate Institute of Medical Education and Research (PGIMER), Chandigarh, India and peripheral blood was obtained from enrolled subjects after an informed consent. The peripheral blood mononuclear cells (PBMCs) were isolated from heparinised blood by Ficoll-Hypaque density gradient centrifugation (HiMedia, Mumbai, India).

\section{Treg Immunophenotyping}

Freshly isolated PBMC were immunophenotyped for Treg number, FoxP3 expression per cell (MFI) and CCR5/CXCR4 expression using fluorophore-conjugated monoclonal antibodies (mAb): anti-CD4 PE/ FITC, anti-CD25 PE-Cy7, anti-CCR5 PE, and anti-CXCR4 PE (all from BD Bioscience, San Jose, CA) for cell surface markers in combination with intracellular Fork-head box protein 3 (FoxP3) mAb conjugated with Alexa488 (eBioscience, San Diego, CA). Samples were acquired into a flowcytometer (FACS Calibur, BD, USA) and analyzed using cell-Quest software (BD Bioscience). For further analysis patients were categorized on the bases of level of surface CD25 expression on CD4 $4^{+}$T-cells: CD4CD25 high (top $2 \%$ with highest CD25 expression), CD4CD25 $5^{\text {intermediate }}$ (middle 15\% with intermediate CD25 expression) and $\mathrm{CD} 4 \mathrm{CD} 25^{\text {low/negative }}$ (lower $83 \%$ with very low or no expression of CD25) cells (Figure 1). Isotype controls were performed for each sample. Absolute counts for different populations were calculated from the total lymphocyte count in the whole blood.

\section{T-cell proliferation assay}

To examine the functional defects of T-cells in these cohorts, proliferative capability of $\mathrm{T}$ cells was assessed on stimulation with mitogen-PHA (phyto-heamagglutinin) by determining the extent of ${ }^{3} \mathrm{H}$-thymindine incorporation. Briefly, $1 \times 10^{5} \mathrm{PBMCs} /$ well were plated into 96-well plates in triplicates in complete RPMI 1640 medium (Sigma) supplemented with $10 \%$ heat-inactivated FCS, $20 \mathrm{IU} / \mathrm{ml}$ penicillin, 20 $\mu \mathrm{g} / \mathrm{ml}$ streptomycin, $25 \mathrm{mM}$ HEPES, and $2 \mathrm{mM} \mathrm{L}$-glutamine for 96 hours at $37^{\circ} \mathrm{C}$ in $5 \% \mathrm{CO}_{2}$, either in presence or absence of PHA $(10 \mu \mathrm{g} /$ $\mathrm{ml}$ ) as stimulant. Eighteen hours prior to termination of the culture, $1 \mu \mathrm{Ci}$ of ${ }^{3} \mathrm{H}$-thymidine (BARC, India) was added to each well. The cells were then harvested on glass fibre mats (Skatron, Belgium) and counted

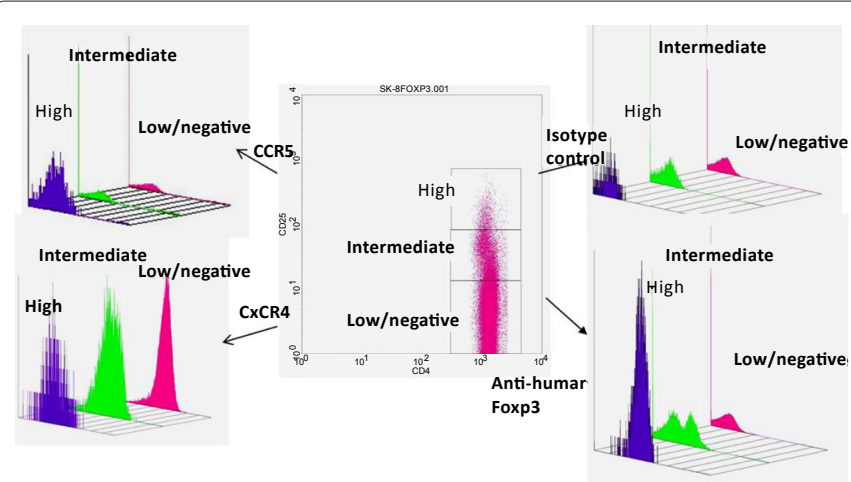

Figure 1: $C D 4+C D 25^{\text {high }}$ Treg in peripheral blood samples by analysis of surface CD25, CCR5, CXCR4 and intracellular FoxP3 on CD4 T-cells. Representative three-color flow cytometric analysis of CD4+CD25 ${ }^{\text {high }}[2 \%]$ and CD4+CD25 intermediate $[15 \%]$ and CD4+CD25 low/negative [83\%] T-cells from HIV subject. For analysis plots, template of both mean fluorescence intensity [MFI] data and percentage positive data [\% of cells expressing a particular antigen] were used.

in liquid scintillation counter (Beckman, USA). All measurements were conducted in triplicates and the results were expressed as the stimulation index (SI), which represented the mean cpm (counts per minute) in the presence of mitogen divided by mean cpm in the absence of the mitogen.

\section{Semi-quantitative estimation of gene expression by RT-PCR analysis}

Total RNA was extracted from EDTA blood using the QIAmp RNA Blood Mini Kit (Qiagen, Germany). RNA was converted into cDNA using Revert Aid ${ }^{\mathrm{TM}}$ First Strand cDNA Synthesis Kit (MBI Fermentas, Lithuania). The first strand CDNA was used in PCR reaction for the relative expression normalized with expression levels of the house keeping gene GAPDH. The primers for CXCR4 Total (CXCR4-T), CXCR4 splice variant 2 (NM_001008540.1), Rac-1 (NM_006908.4), NF- $\kappa B$ (NM_003998.3) were as follows: GAPDH forward, 5' -CAAGGTCATCCATGACAACTTTG-3' and reverse, $5^{\prime}$-GTCCACCACCCTGTTGCTGTAG-3'; CXCR4-T forward, 5' - CTTCTACCCCAATGACTTGTGG-3' and reverse, 5' - AATGTAGTAAGGCAGCCAACAG-3'; CXCR4 splice variant-2 forward, $5^{\prime}$-AACCAGCGGTTACCATGGAG-3' and reverse, 5'-CCCACAATGCCAGTTAAGAAGA-3'; Rac-1 forward, 5'-TTACGCCCCCTATCCTATCCGCA-3' and reverse, 5'-GCGCCGAGCACTCCAGGTATT-3'; NF- $\kappa$ B forward, $5^{\prime}$-TTCACCAAGCCTGCCCTTGGAC-3' and reverse, 5'-CTGTCTTGTGGACAACGCAGTGGAATTTTAGG-3'. The thermal cycle reprogramming was as follows: denaturation at $95^{\circ} \mathrm{C}$ for $5 \mathrm{~min}$, followed by $35 \mathrm{cycles}$ at $95^{\circ} \mathrm{C}$ for $30 \mathrm{sec}$ and annealing at $58^{\circ} \mathrm{C}$ for GAPDH, $64^{\circ} \mathrm{C}$ for CXCR4-T, $56^{\circ} \mathrm{C}$ for CXCR4 splice variant $-2,66^{\circ} \mathrm{C}$ for Rac- 1 and $62^{\circ} \mathrm{C}$ for NF- $\kappa B$ for 30 seconds, extension was carried at $72^{\circ} \mathrm{C}$ for $1 \mathrm{~min}$.

\section{Statistical analysis}

Data are expressed as mean $\pm \mathrm{SE}$ and ranges. Difference between groups was tested by one-way student's $t$-test. Correlation analysis was done using the non-parametric Spearman's Rank Correlation Coefficient. Linear Regression Analysis was carried out and the residuals were calculated. The level of significance was set at $\mathrm{p}<0.05$.

\section{Results}

\section{Demographic and Immunological characteristics}

The cross-sectional study included a total of 67 subjects: 27 HIV-1 
Citation: Toor JS, Sharma A, Kamboj SS, Arora SK (2013) Differential Expression of Rac-1, CXCR4 and CCR5 on CD4 T-Cells at Different Stages of HIV-1 Disease Relate To Its Progression in Therapy Naïve Individuals. J AIDS Clin Res 4: 207. doi:10.4172/2155-6113.1000207

Page 3 of 8

patients (age range between 21-53 years and CD4+ T-cell count range: 32-854 cells/ $\mu$ l), 12 active PTB patients (age range between 21-65 years and CD4+ T-cell count range: $326-1368$ cells/ $\mu$ l), 8 HIV-PTB coinfected patients (age range between 17-34 years and CD4+ T-cell count range: $30-273$ cells/ $\mu \mathrm{l}$ ), and $20 \mathrm{HC}$ (age range between $22-40$ years and CD4+ T-cell count range: 444-1375 cells/ $\mu \mathrm{l})$. Table 1 summarizes their clinical characteristics.

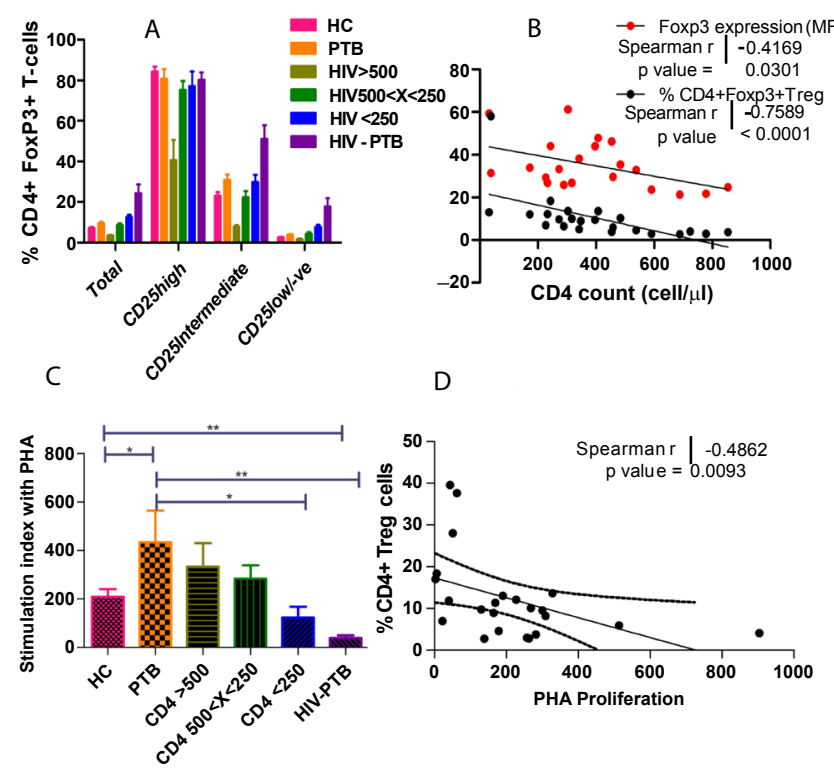

Figure 2: Association between increase in percent CD4+ Treg cells with disease progression [drop of CD4 count] and suppressive T-cell proliferation to PHA in HIV-1 individuals. A. Frequency of CD4+Foxp3+ T-regulatory cells in HC, PTB, HIV-1 infected with or without PTB co-infection within CD4 T-cell [Total], CD4+CD25 high [CD25 high], CD4+CD25 intermediate [CD25 intermediate] and $\mathrm{CD} 4+{ }^{\mathrm{CD} 25 l o w / n e g a t i v e}[\mathrm{CD} 25 \mathrm{low} /$-ve] sub-population. PBMC were stained with CD4-PE, CD25-PE-Cy7, and FoxP3-Alexa488. Data are expressed as Means with SEM [standard error of mean] of percentage cells positive for FoxP3.B.Significant negative correlation between percent CD4+FoxP3+ Tregs and FoxP3 expression per cell [MFI] with CD4 count in PBMC from HIV patients.C. Proliferative T-cell response profile to $\mathrm{PHA}$ [non-specific stimulation for 96 hours]. Stimulation indices were determined by comparison with paired unstimulated cells from each individual. Data are expressed as Means with SEM [standard error of the mean] of stimulation indices. D. Negative positive correlation between percent Treg within CD4 T-cells. The solid line is the linear regression of the points and dotted lines are the $95 \%$ confidence band for the mean. Rho and $p$ values are Spearman rank correlation test.
High CD4+FoxP3 frequency correlates with poor T-cell stimulation in HIV-PTB co-infected and HIV advanced disease individuals

Within the HIV-1 infected group, there was significantly low frequency of Treg in individuals with CD4 count $>500$ cells $/ \mu$ (mean \pm SEM: $3.49 \pm 0.31, \mathrm{p}=0.0003$ ) as compared to other groups and HC (Figure 2a) hence, indicating early selective depletion of Treg cells. This is followed by increase in the mean percent frequency of Treg as the disease progresses. Though statistically non-significant, we did see an increase in the Treg frequency in HIV-1 patients with $M t b$ coinfection when compared with only HIV-infected individuals with similar CD4 count $(<250$ cells/ $\mu \mathrm{l})$. Overall, there was a significant inverse relationship $(\mathrm{p}<0.0001)$ between percent Treg as well as FoxP3 expression with the disease progression in terms of CD4 count (Figure 2b). Following PHA stimulation, mean proliferative index of T-cells from HIV-PTB co-infected individuals was significantly lower (mean \pm SEM: $39.90 \pm 10.00, \mathrm{p}=0.0011$ ) as compared to HC (mean \pm SEM: 204.7 \pm 30.76 ). Individuals with only PTB or HIV infected with CD4 count $>500$ cells $/ \mu$ l had higher proliferative index (mean \pm SEM: $434.0 \pm 138.8$, $\mathrm{p}=0.0390$ and $332.9 \pm 97.74, \mathrm{p}=0.1596$ respectively). Overall, there was a significant negative correlation between T-cell proliferation and HIV1 disease progression (Figures $2 \mathrm{c}$ and $2 \mathrm{~d}$ ). These results suggest that reduced T-cell proliferative potential in HIV-PTB co-infected as well as only HIV infected in advanced stage of disease is due to increased frequency of FoxP3+ Treg cells in these individuals.

\section{HIV-1 subjects in early stage of disease had significantly} higher number of CD4+CD25 ${ }^{\text {high }}$ Treg cells expressing CCR5

CD4 T-cell sub-populations were examined for surface expression of CCR5, which were calculated as percentage of total analyzed CD4 T-cells in peripheral blood. All HIV-1 infected individuals, irrespective of $M t b$ co-infection, had significantly higher percentage of CD4 T-cells expressing CCR5 as compared to HC. This difference was not seen in individuals with PTB infection (Table 2). However, looking at the $\mathrm{CD} 4+\mathrm{CD} 25^{\text {high }}$ Treg population within the CD4 T-cells, there was significantly higher percentage of cells with CCR5 expression in PTB individuals (mean \pm SEM: $19.83 \pm 2.52, \mathrm{p}=0.0226)$ in comparison to HC (mean \pm SEM: $12.72 \pm 1.29$ ) (Figure 3a). Similar results were seen in early stage of disease in only HIV-1 infected individuals having normal CD 4 count (mean \pm SEM: $32.17 \pm 7.15, p=0.0021$ ). Interestingly, there was a drop in the CCR5+ Treg cell numbers with decrease in CD4 count. There was significantly lower frequency of these cells in HIV patients

\begin{tabular}{|c|c|c|c|c|c|c|c|}
\hline Patient groups & $\mathrm{HC}$ & PTB & & HIV-1 & ubtype C & & HIV-PTB \\
\hline Patient subgroups & & & Total HIV & Above 500 cells $/ \mu \mathrm{l}$ & $500>X>250$ cells $/ \mu \mathrm{l}$ & Below 250 cells $/ \mu \mathrm{l}$ & \\
\hline Subjects & 20 & 12 & 27 & 8 & 10 & 9 & 8 \\
\hline Age [Median years] & 28.5 & 34 & 32 & 27 & 30 & 37 & 30 \\
\hline$\%$ Males & 60 & 100 & 59.3 & 62.5 & 60 & 55.6 & 75 \\
\hline$\%$ Females & 40 & & 40.7 & 37.5 & 40 & 44.4 & 25 \\
\hline WBC count & 7300 & 10900 & 6300 & 6800 & 6250 & 5800 & 6800 \\
\hline T-cell count [CD3+] & 1401 & 970.5 & 1738 & 2403 & 1811 & 1475 & 1095 \\
\hline Th cells count [CD3+CD4+] & 849 & 459.5 & 345.0 & 706 & 348 & 172 & 171 \\
\hline Lymphocytes [CD45+] & 1954 & 1579 & 2377 & 3477 & 2424 & 1587 & 1888 \\
\hline $\mathrm{Hb}$ g/dl & 13.8 & 12.5 & 13.30 & 14.2 & 14.45 & 10.2 & 10 \\
\hline
\end{tabular}

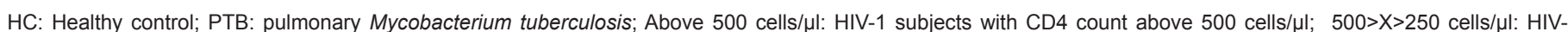

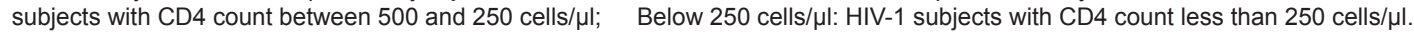

Table 1: Demographic and immunological characteristic of individuals within studied subgroups. Data expressed as median.There was no significant difference between CD4 count from HIV-1 subjects with CD4 count $>250$ cells/ul and HIV-1/PTB co-infected individuals. Strangely, we found significantly low mean CD4 count in individuals with active PTB [HIV-1/2 negative] when compared to HC. 
Citation: Toor JS, Sharma A, Kamboj SS, Arora SK (2013) Differential Expression of Rac-1, CXCR4 and CCR5 on CD4 T-Cells at Different Stages of HIV-1 Disease Relate To Its Progression in Therapy Naïve Individuals. J AIDS Clin Res 4: 207. doi:10.4172/2155-6113.1000207

Page 4 of 8

\begin{tabular}{|c|c|c|c|}
\hline Groups & Mean & Std. Error & $P$ value \\
\hline HC & 2.731 & 0.2586 & \\
\hline PTB & 3.295 & 0.8588 & 0.3215 \\
\hline HIV-1 [CD4 >500 cells/ul & 3.876 & 0.4110 & 0.0243 \\
\hline HIV-1 [CD4 500>x>250 cells/ $\mu \mathrm{l}$ & 5.254 & 1.208 & 0.0194 \\
\hline HIV-1 [CD4 <250] & 5.835 & 1.569 & 0.0127 \\
\hline HIV-PTB & 9.424 & 4.000 & 0.0243 \\
\hline
\end{tabular}

Table 2: Comparison of frequency of CCR5 expression on CD4+ T-cells in individuals between healthy controls and other diseased patient groups. Data are expressed as Means with SEM [standard error of the mean] of percentage CD4 T-cells positive for CCR5 and $P$ value less than 0.05 indicates significant difference when compared with healthy controls.

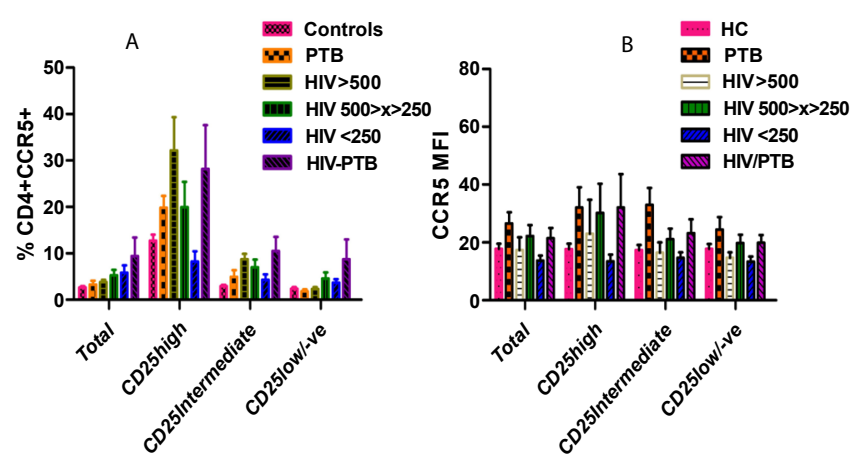

Figure3: Comparison of CCR5 co-receptor expression on CD4 T-cell in HIV infected and the effect of PTB co-infection. A. Comparison of frequency of CCR5 positive CD4 T-cell, CD4+CD25 high [Treg], CD4+CD25 intermediate and CD4+CD25low/negative sub-population in HC, patients with PTB, HIV-1 infected with or without PTB co-infection. Data are expressed as Means with SEM [standard error of the mean] of percentage cells positive for CCR5. B. Comparison of CCR5 expression per cell on CD4 T-cell, CD4+CD25 high [Treg], $\mathrm{CD} 4+\mathrm{CD} 25^{\text {intermediate }}$ and $\mathrm{CD} 4+^{\mathrm{CD} 25 \text { low/negative }}$ sub-population. PBMC were stained with CD4-FITC, CD25-PE-Cy7, and CCR5-PE. Data are expressed as Means with SEM [standard error of the mean] of MFI of cells positive for CCR5.

with CD4 count $<250$ cells $/ \mu$ l $(\mathrm{p}=0.002)$ in comparison to those with CD4 count $>500$ cells $/ \mu$. In individuals with PTB co-infection, there was a significant increase in CCR5+ Treg number (mean \pm SEM: 28.15 \pm 9.41) when compared with only HIV-1 infected individuals with similar CD4 count (CD4 count $<250(\mathrm{p}=0.0260))$. There was however no significant change in CCR5 expression seen is CD4CD25 $5^{\text {low/ngative }}$ subpopulation among these groups (Figure 3a). This indicates that in the early stage of HIV infection there is higher number of Treg cells having very high CD25 expression co-expressing CCR5 also which may be the reason for their early depletion in these individuals.

M.tuberculosis co-infection in HIV-1 induces CCR5 expression in CD25 $5^{\text {high }}$ and CD25 ${ }^{\text {intermediate }}$ Treg subpopulations but not in $\mathrm{CD} 25^{\text {low/negative }}$ cells

Looking at the quantitative (MFI) expression of CCR5 on CD4 T-cell subsets, we observed significantly lower expression in HIV infected individuals in advanced stage of disease (CD4 count $<250$ cells/ $\mu$ l (mean \pm SEM: $13.63 \pm 1.79, \mathrm{p}=0.0496)$ ) as compared to healthy controls (mean \pm SEM: $17.84 \pm 1.68$ ), while it was significantly in PTB subjects (mean \pm SEM: 26.52 $\pm 3.93, \mathrm{p}=0.0214$ ) (Figure $3 \mathrm{~b}$ ). Presence of PTB co-infection had similar effect in HIV-1 individuals with significantly higher expression of CCR5 (mean \pm SEM: 21.48 \pm 3.54 , $\mathrm{p}=0.0364$ ) as compared to only HIV infected patients with similar CD4 count (i.e. $<250$ cells $/ \mu$ l: mean \pm SEM: $13.63 \pm 1.79$ ). This quantitative increase in the CCR5 expression on CD4 T-cell in PTB individuals was seen on $\mathrm{CD} 4+\mathrm{CD} 25^{\text {high }}$ and $\mathrm{CD} 4+\mathrm{CD} 25^{\text {intermediate }}$ cell populations but not on $\mathrm{CD} 4+\mathrm{CD} 25^{\text {low/negative }}$ (mean \pm SEM: $24.44 \pm 4.28, \mathrm{p}=0.0549$ ) subpopulation indicating the presence of $M t b$ influences the expression of CCR5 on CD25+ Treg cells only and not the CD25 $5^{\text {low/negative }}$ effector cells.

Significant decrease in the frequency of CXCR4+ cells in CD4+CD25 $5^{\text {low/negative }}$ sub-population of HIV-PTB co-infected individuals

There was no significant difference seen in frequency of CXCR4+ cells within HIV-1 sub-groups with the disease progression. However, we found a decrease in the percentage of CXCR4+ cells in HIV-PTB co-infected individuals (mean \pm SE: $86.43 \pm 4.95$ ) when compared with only PTB infected (mean \pm SE: $94.99 \pm 1.76, \mathrm{p}=0.0232$ ) and $\mathrm{HC}$ (mean \pm SE: $95.28 \pm 1.13, \mathrm{p}=0.048$ ) (Figure $4 \mathrm{a}$ ). Interestingly, this difference was not seen either in Treg population or in CD25 $5^{\text {intermediate }}$ sub-populations but only in the CD25 $5^{\text {low/negative }}$ populations. Further, CD25 high Treg cells showed lower frequency of CXCR4+ cells in comparison to CD25 $25^{\text {low }}$ negative in all studied subjects. These results indicate that significantly lower number of CD25 $5^{\text {low/negative }}$ effector cells expressing CXCR4 receptor were seen in PTB co-infected individuals as compared to only HIV1 infected individuals having similar CD4 count. On the other hand, quantitatively the CXCR4 expression (MFI) was significantly increased on CD4 cells in subjects with only PTB infection (mean \pm SEM: 148.4

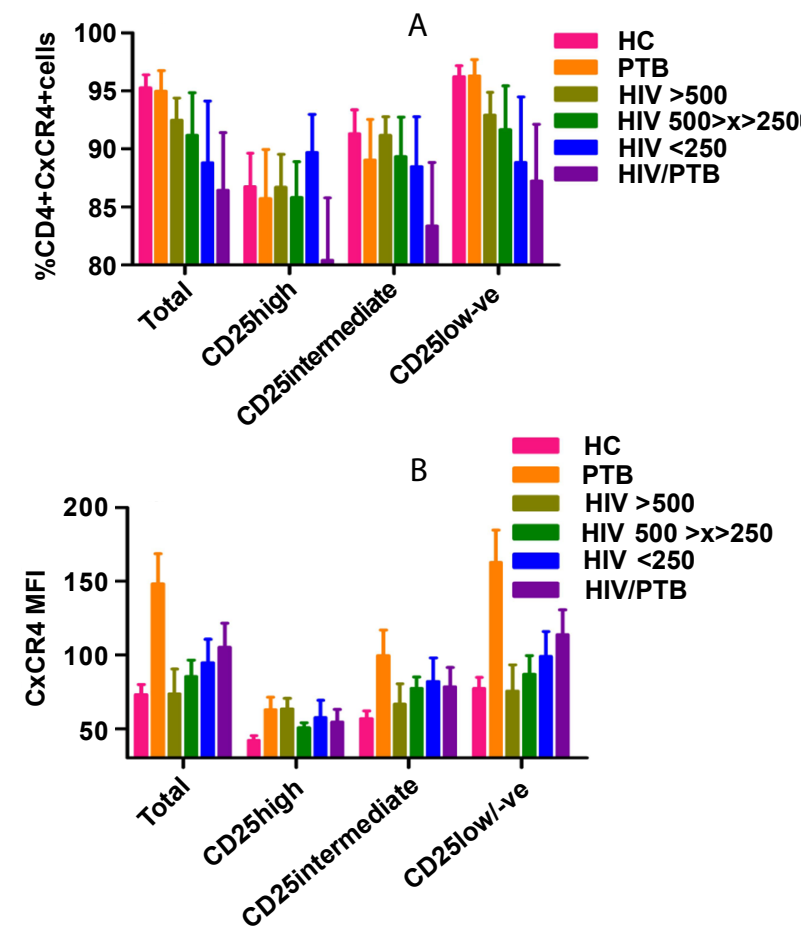

Figure 4: Comparison of CXCR4 co-receptor expression on CD4 T-cell in HIV infected and the effect of PTB co-infection. A. Frequency of CXCR4+

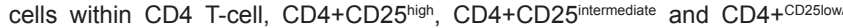
negative sub-population in $\mathrm{HC}$, patients with PTB, HIV-1 infected with or without PTB co-infection. Data are expressed as Means with SEM [standard error of the mean] of percentage cells positive for CXCR4. B. Comparison of CXCR4 expression per cell on CD4 T-cell, CD4+CD25 $5^{\text {high }}$ [Treg], CD4+CD25 $5^{\text {intermediate }}$ and CD4+CD25low/negative sub-population. PBMC were stained with CD4-FITC, CD25-PE-Cy7, and CXCR4-PE. Data are expressed as Means with SEM [standard error of the mean] of MFI of cells positive for CXCR4. 

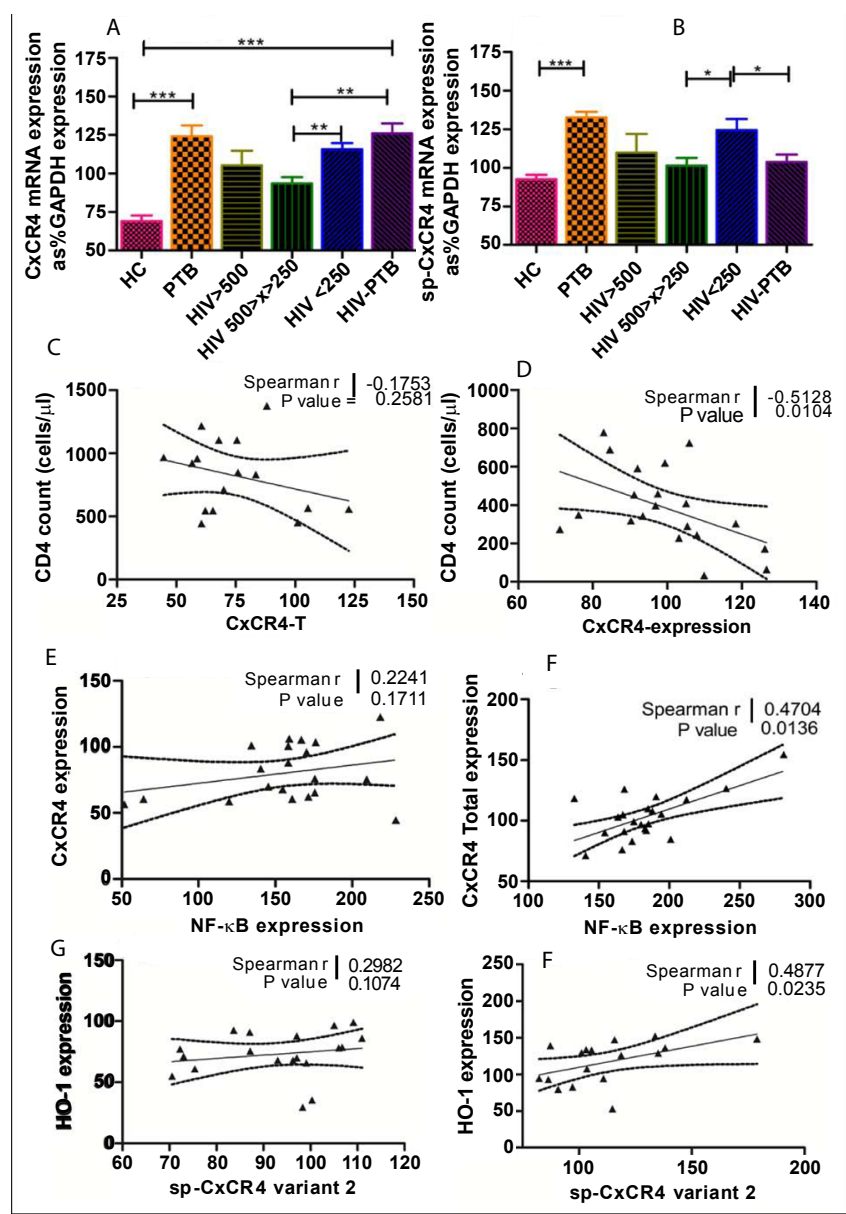

Figure 5: CXCR4 expression. A. \& B. Total CXCR4 and CXCR4 splice varian 2 mRNA relative gene expressions as percent of GAPDH in unstimulated PBMCs from HC, patients with PTB, HIV-1 infected with or without PTB coinfection. C. \& D. CXCR4 mRNA relative gene expression is up-regulated in HIV-1 infected subjects with disease progression with significant negative correlation with absolute CD4 count. E. \& F. NF-kB positively associated with CXCR4 variants expression in HIV-1 patients. The relative NF-KB mRNA expression in PBMC cells positively correlated with CXCR4 expression in HIV1 subjects and not in healthy controls $[\mathrm{HC}]$. G. \& $\mathbf{H}$. Relative HO-1 mRNA expression in PBMCs positively correlate with CXCR4 variant 2 in HIV-1 subjects and not in healthy controls. The solid line is the linear regression of the points and dotted lines are the $95 \%$ confidence band for the mean. Rho and $p$ values are Spearman rank correlation test.

$\pm 20.40)$ as compared to the HC (mean \pm SEM: $73.1 \pm 6.90, p=0.0011)$. The expression was also higher in PTB-HIV co-infected subjects (although statistically non-significant at mean \pm SEM: $94.77 \pm 16.05$ ), when compared to only HIV-1 infected individuals with comparable CD 4 count (count $<250$ cells/ $\mu$; mean \pm SEM: $105.3 \pm 16.16$ ), but was significantly higher than HC (mean \pm SEM: $73.10 \pm 6.90, p=0.0342$ ). Interestingly, this significant difference in CXCR4 expression in PTB subjects was mainly contributed by $\mathrm{CD} 25^{\text {low/negative }}$ subpopulation showing nearly two fold increase in its expression in comparison to HC $(\mathrm{p}=0.0011)$. These results indicate that $M t b$ infection favors increase in CXCR4 expression on CD25 $5^{\text {low/negative }}$ effector cell subset.

Upregulation of CXCR4 and its splice variant-2 expression is associated with HIV disease progression and presence of Mtbco-infection

There was a trend of increase in the CXCR4 expression in HIV-1 patients with the disease progression (Figure 5A, 5B, 5B). Further with the onset of AIDS the HIV-PTB co-infected individuals had higher CXCR4 expression (mean \pm SEM: $126.0 \pm 6.2, \mathrm{p}=0.1201$ ) in comparison to HIV-1 subjects with similar CD4 count (CD4 count $<250$ cells/ $\mu \mathrm{l})$ though statistically non-significant. Similar results were observed in CXCR4 variant-2 expression with significantly high expression in PTB and HIV-1 patients (Figure 5B). Interestingly, there was significant decrease in the expression of variant-2 with PTB co-infection (mean \pm SEM: $124.4 .6 \pm 7.2$ ) when compared to only HIV-1 infected subjects with CD 4 count $<250$ cells $/ \mu$ ( mean \pm SEM: $103.6 \pm 5.0, p<0.0175$ ). This suggests that with the progression of HIV disease CXCR4 expression is increased both in only HIV infected as well as PTB co-infected individuals. Further, this increase in CXCR4expression positively correlated with NF- $\mathrm{KB}$ expression in HIV-1 subjects (Figure $5 \mathrm{E}$ and 5f). This significant positive correlation of CXCR4 was extended with hemeoxygenase 1 (HO-1) but only with variant 2 (Figure $5 \mathrm{G}$ and $5 \mathrm{H}$ ).

\section{Mycobacterium tuberculosis infection results in down regulation of Rac-1 expression in $\mathrm{HIV}-1$ patients}

Rac1 expression was significantly lower in PTB patients (mean \pm SEM: $112.4 \pm 4.7, \mathrm{p}=0.0063)$, HIV- 1 subjects with CD4 count $>500$ cells $/ \mu \mathrm{l}$ (mean \pm SEM: $109.7 \pm 9.5, \mathrm{p}=0.0283$ ) and HIV-PTB co-infected individuals (mean \pm SEM: $110.1 \pm 2.3, \mathrm{p}=0.0062$ ) when compared to healthy controls (mean \pm SEM: $131.7 \pm 4.5$ ). We saw a trend of initial decrease in Rac1 expression in early stage of HIV-1 infection followed by returning to normal expression as the disease progresses (Figure 6a). Further, there was a significant decrease in the Racl expression in HIV individuals with onset of $M t b$ co-infection when compared with individuals infected with HIV-1 only with CD4 count between 250 and 500 cells $/ \mu \mathrm{l}(\mathrm{p}=0.0128)$ and $<250$ cells $/ \mu \mathrm{l}(\mathrm{p}=0.0325)$. This indicates that onset of $M t b$ infection down regulates the expression of Rac-1 gene making it unavailable to maintain the CXCR4 conformation suitable for HIV utilization. In addition, Rac1 significantly, positively correlates with immunosuppressive genes FoxP3 (Figure 6F and 6G) and HO-1 (Figure 6H and 6I) in HIV-1 individuals only (unpublished personal data).

\section{Discussion}

The results in the present study elucidate some of the cellular factors manipulated by HIV-1 at different stages of disease progression and in the event of M.tuberculosis co-infection. It has earlier been revealed that CCR5 and CXCR4, the major co-receptors critical for viral entry into the host cells, are differentially expressed on CD4+ T-cells, and their relative expression is closely associated with disease pathogenesis [18-24]. We studied their expression on different subsets of T-cells including T-regulatory cells and evaluated their role in changing the frequency of these cells with disease progression. We also evaluated the change in Rac1 expression, critical for functional CXCR4 receptor [10], for it's possible role in M5 to T4 HIV-1 viral shift based on availability of co-receptor.

We found a significantly low frequency of FoxP3+CD4 cells in early stage of disease followed by a gradual increase with the progression of disease. These observations prompted us to look at the expression of CCR5 and CXCR4 on Treg cell sub population for their possible role in influencing the change in Treg cell frequency with HIV disease progression. Frequency of CD4 T cells expressing CCR5 was found to be up-regulated in HIV-1 infected individuals when compared to the healthy controls, irrespective of the stage of the disease, which is in concordance with the previous findings [25-27]. There was higher percentage of CD25 high Treg cells expressing CCR5 in comparison to 

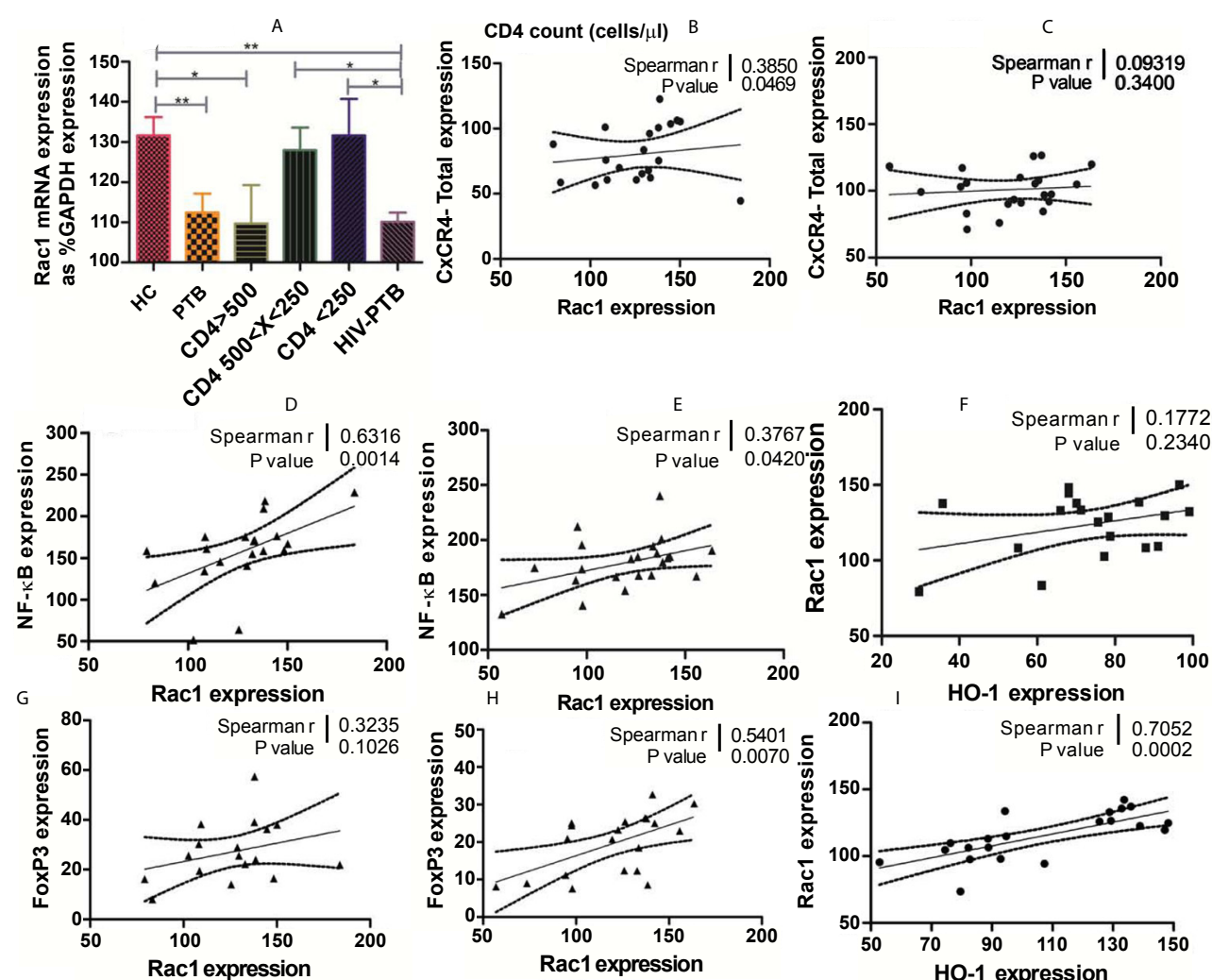

Figure 6: Rac-1 expression. A.Rac-1 mRNA relative gene expression as percent of GAPDH in unstimulated PBMCs from HC, patients with PTB, HIV-1 infected with or without PTB co-infection. B. \& C. Rac-1 positively correlated with relative mRNA expression of CXCR4-T, though this scenario is broken in HIV-1 subjects. D. \& E. Significant positive correlation of Rac1 expression with NF-KB, in both healthy and HIV-1 subjects, independent of the disease condition.F. \& G.There was significant positive correlation between Rac1 with HO-1 in HIV-1 subjects.H. \& I.There was no correlation of FoxP3 with Rac1 in healthy controls but we found significant correlation in HIV-1 subjects. The solid line is the linear regression of the points and dotted lines are the $95 \%$ confidence band for the mean. Rho and $p$ values are Spearman rank correlation test.

CD25 $5^{\text {low/negative }}$ effector cells $(\mathrm{p}<0.0001)$ and which could make them preferential targets for R5 viral attack in the initial stages of disease (Figure 3a). On the other hand, in advanced stage of the disease with CD4 count $<250$ cells/ $\mu$, the number of CCR5 positive Treg were significantly lower when compared to HIV-1 individuals in early stage of disease $(\mathrm{p}=0.0022)$. With previous reports in non-subtype $\mathrm{C}$ infections, the depletion of CCR5 expressing memory cells in acute infection may drive viral evolution towards CXCR4 [28,29], and recent reports showing about $30 \%$ of CXCR4-utilising viruses in untreated and treated HIV-1 subtype C infected adults from South Africa, Malawi, and Zimbabwe, suggesting a shift in viral properties [30-32]. This change in CCR5 expression might be responsible for increase in the frequency of Treg cells in the advanced stages of the disease.

On the contrary we observed a lower frequency of CD4 T-cells expressing chemokine receptor CXCR4, in the later stages of HIV disease when compared to healthy controls, although statistically nonsignificant (Figure 4a). This is in concordance with previously reported observation in HIV subjects [25-27]. It is interesting to note that there is a reverse scenario when we considered the quantitative expression of CXCR4 per cell (MFI) on CD4 cells in these subjects (Figure 4b). There was an increase in the CXCR4 expression in advanced stages of HIV1 when compared to asymptomatic early stage HIV-1 subjects. This could explain decrease in the frequency of CXCR4 positive CD4 T-cells in later stages of the disease due to X4 tropic viral shift and killing of these cells. Again, contrary to CCR5, there was significant decrease in percent CD4 T-cells expressing CXCR4 ( $\mathrm{p}=0.0033)$ even quantitatively (MFI, $\mathrm{p}=0.0004$ ) in $\mathrm{CD} 25^{\text {high }}$ Treg when compared with CD25 $5^{\text {low/negative }}$ cells in healthy controls. This could be a possible explanation for the decrease in percent of CXCR4 expressingCD4 T-cells in CD25 low/negative subpopulation of cells within HIV-1 groups negatively correlating with disease progression but with no effect on Treg cell number with low expression of CXCR4.

However the situation was totally different if we look at the data from patients infected with only $M t b$ or co-infected with HIV. It is well known that $M t b$ co-infection in HIV may create a microenvironment enhancing the productive infection of T-cells by HIV [33-36]. We observed that HIV-1 individuals with active pulmonary tuberculosis displaying increased CCR5 $(\mathrm{p}=0.0364$, Figure $3 \mathrm{~b})$ and not CXCR4 $(\mathrm{p}=0.1914$, Figure $4 \mathrm{~b})$ expression per cell (MFI) on CD4 T-cells when compared with HIV-1 subjects with similar CD4 count $(<250$ cells/ $\mu \mathrm{l})$ suggesting preferential utilization of CCR 5 rather than CXCR 4 by virus in co-infected individuals. This falls in line with reports which demonstrated that R5 viral variants were preferentially recovered from patients with active TB [37]. Furthermore, increased frequency of CD4 cells expressing CCR5 and up-regulated expression limited to $\mathrm{CD} 25^{\text {high }}$ and CD25 $5^{\text {intermediate }}$ populations only in co-infected individuals with no significant change in CD25 $5^{\text {low/negative }}$ subpopulation indicated the influence of MTB on these two subpopulations only making them more vulnerable to HIV-1 infection. Whereas, a significant decrease in frequency of CXCR4+ T-cells in co-infected individuals could mainly 
Citation: Toor JS, Sharma A, Kamboj SS, Arora SK (2013) Differential Expression of Rac-1, CXCR4 and CCR5 on CD4 T-Cells at Different Stages of HIV-1 Disease Relate To Its Progression in Therapy Naïve Individuals. J AIDS Clin Res 4: 207. doi:10.4172/2155-6113.1000207

Page 7 of 8

be attributed to a significant decrease in CD25 $5^{\text {low/negative }} \mathrm{CD} 4 \mathrm{~T}$-cell subpopulation. On the other hand, significantly increased CXCR4 expression on $\mathrm{CD} 25^{\text {low/negative }}$ cells during $M t b$ infection makes it the main population affected in co-infected individuals as evidenced by their low frequency in these individuals. Thus, the data suggests that M.tuberculosis co-infection in HIV-1 individuals seems to be selectively affecting the differential expression of these chemokine receptors on different subpopulations of cells thereby leading to their selective depletion during different stages of disease.

Over the course of infection, the co-receptor usage of HIV changes from CCR5 to CXCR4 in 50\% of the infected individuals [1,7,38-41]. It is generally believed that relatively late appearance of X4 virus variants is driven by evolution of virus population during the course of disease [42]. This assumption is in conflict with viral property of rapid turnover of about $10^{10}$ to $10^{12}$ virions every two days combined with the high mutation rate of HIV [42-50]. This should result in emergence of X4 variants fairly early during infection, especially because, in some cases, only two mutations are thought to be necessary for co-receptor switch. Hence factors that influence this evolution of the virus remain largely unknown. It has been demonstrated recently that Racl is specifically involved in regulating the conformation of CXCR4, thereby controlling signaling efficiency of the receptor. Furthermore, the conformation adopted by CXCR4 after Rac1 inhibition blocks HIV-1 infection, most probably by interfering with virus binding and subsequent entry into the host cells [10]. It was interesting to note in our study that Rac1 expression was significantly lower in patients in early stage of disease when compared to healthy controls (Figure 6A). With the disease progression we observed an increase in its expression in individuals infected with only HIV-1. These results indicate and support the other previous findings that initially there is $\mathrm{R} 5$ virus predominance as there is low Rac1 expression and X4 viruses even present are unable to use CXCR4 co-receptor. Rac1 has no effect on CCR5 conformation or its utilization by the virus [10]. Though, in advanced stage of HIV-1 infection we found an up-regulatedRacl expression which would make CXCR4 conformationally favorable to HIV-1 attachment and possibly is one of the reasons for R5 to X4 viral shift with HIV disease progression. We found a significant positive correlation of Rac1 with NF- $\kappa B$ (Figure 6D) and CXCR4 (Figure 6B) expression in healthy controls. Though this correlation of Rac1 and CXCR4 was not obvious in HIV-1 patients (Figure $6 \mathrm{C}$ ), NF- $\mathrm{\kappa B}$ retained significant positive correlation in HIV1 subjects indicating this pathway not being affected by the disease condition (Figure 6E). However, with M. tuberculosis co-infection, the Rac1 was significantly down-regulated making available CXCR4 receptors non-utilizable by the virus. This observation is in line with the finding that R5 viral variants were preferentially recovered from HIV infected patients with active M. tuberculosis [51].

Overall, we have recognized novel inter-relationships of genes and their behavior in HIV-1 therapy naïve individuals, highlighting how the virus manipulates the host machinery during $M t b$ co-infection to its advantage. Though, significant correlation of NF- $\kappa B$ with Rac1 in both healthy and HIV-1 subjects was observed, a highly significant correlation between FoxP3, HO-1 and Rac-1 (unpublished personal data) was seen in HIV-1 subjects with CXCR4 variant 2 showing positive correlation with $\mathrm{HO}-1$, these findings need further attention to look at their clinical implication and disease outcome.

\section{Acknowledgements}

Authors thankfully acknowledge the funding support by Department of Biotechnology (DBT), Ministry of Science and Technology, Govt. of India

\section{References}

1. Berger EA, Murphy PM, Farber JM (1999) Chemokine receptors as HIV-1 coreceptors: roles in viral entry, tropism, and disease. Annu Rev Immunol 17 657-700.

2. de Mendoza C, Rodriguez C, García F, Eiros JM, Ruíz L, et al. (2007) Prevalence of $X 4$ tropic viruses in patients recently infected with HIV-1 and lack of association with transmission of drug resistance. J Antimicrob Chemother 59: 698-704.

3. Frange P, Galimand J, Goujard C, Deveau C, Ghosn J, et al. (2009) High frequency of $X 4 / D M$-tropic viruses in PBMC samples from patients with primary HIV-1 subtype-B infection in 1996-2007: the French ANRS CO06 PRIMO Cohort Study. J Antimicrob Chemother 64: 135-141.

4. Wilkin TJ, Goetz MB, Leduc R, Skowron G, Su Z, et al. (2011) Reanalysis of coreceptor tropism in HIV-1-infected adults using a phenotypic assay with enhanced sensitivity. Clin Infect Dis 52: 925-928.

5. Brumme ZL, Goodrich J, Mayer HB, Brumme CJ, Henrick BM, et al. (2005) Molecular and clinical epidemiology of CXCR4-using HIV-1 in a large population of antiretroviral-naive individuals. J Infect Dis 192: 466-474.

6. Hunt PW, Harrigan PR, Huang W, Bates M, Williamson DW, et al. (2006) Prevalence of CXCR4 tropism among antiretroviral-treated HIV-1-infected patients with detectable viremia. J Infect Dis 194: 926-930.

7. Schuitemaker H, Koot M, Kootstra NA, Dercksen MW, de Goede RE, et al. (1992) Biological phenotype of human immunodeficiency virus type 1 clones at different stages of infection: progression of disease is associated with a shift from monocytotropic to T-cell-tropic virus population. J Virol 66: 1354-1360.

8. Weiser B, Philpott S, Klimkait T, Burger H, Kitchen C, Burgisser P, et al. [2008] HIV-1 coreceptor usage and CXCR4-specific viral load predict clinical disease progression during combination antiretroviral therapy. AIDS 22: 469-479.

9. Zhou H, Xu M, Huang Q, Gates AT, Zhang XD, et al. (2008) Genome-scale RNAi screen for host factors required for HIV replication. Cell Host Microbe 4 495-504.

10. Zoughlami Y, Voermans C, Brussen K, van Dort KA, Kootstra NA, et al. (2012) Regulation of CXCR4 conformation by the small GTPase Rac1: implications for HIV infection. Blood 119: 2024-2032.

11. Evans P, Dampier W, Ungar L, Tozeren A (2009) Prediction of HIV-1 virus-host protein interactions using virus and host sequence motifs. BMC Med Genomics 2: 27 .

12. Samuel CE (2006) Virus-host interaction minireview series: human immunodeficiency virus, hepatitis $\mathrm{C}$ virus, and influenza virus. J Biol Chem 281: 8305-8307.

13. Lopes JE, Torgerson TR, Schubert LA, Anover SD, Ocheltree EL, et al. (2006) Analysis of FOXP3 reveals multiple domains required for its function as a transcriptional repressor. J Immunol 177: 3133-3142.

14. Alcamí J, Laín de Lera T, Folgueira L, Pedraza MA, Jacqué JM, et al. (1995) Absolute dependence on kappa $B$ responsive elements for initiation and Tatmediated amplification of HIV transcription in blood CD4 T lymphocytes. EMBO J 14: 1552-1560

15. Duh EJ, Maury WJ, Folks TM, Fauci AS, Rabson AB [1989] Tumor necrosis factor alpha activates human immunodeficiency virus type 1 through induction of nuclear factor binding to the NF-kappa B sites in the long terminal repeat. Proc Natl Acad Sci U S A 86: 5974-5978.

16. Sgarbanti M, Remoli AL, Marsili G, Ridolfi B, Borsetti A, et al. (2008) IRF-1 is required for full NF-kappaB transcriptional activity at the human immunodeficiency virus type 1 long terminal repeat enhancer. J Virol 82: 3632 3641.

17. Holmes D, Knudsen G, Mackey-Cushman S, Su L (2007) FoxP3 enhances HIV1 gene expression by modulating NFkappaB occupancy at the long terminal repeat in human T cells. J Biol Chem 282: 15973-15980.

18. Kuiken C, Foley B, Marx P, Wolinsky S, Leitner T, et al. (2008) HIV Sequence Compendium 2008.

19. Hamlyn E, Hickling S, Porter K, Frater J, Phillips R, et al. (2012) Increased levels of CD4 T-cell activation in individuals with CXCR4 using viruses in primary HIV-1 infection. AIDS 26: 887-890.

20. Lathey JL, Tsou J, Brinker K, Hsia K, Meyer WA 3rd, et al. (1999) Lack of autologous neutralizing antibody to human immunodeficiency virus type 1 (HIV- 
Citation: Toor JS, Sharma A, Kamboj SS, Arora SK (2013) Differential Expression of Rac-1, CXCR4 and CCR5 on CD4 T-Cells at Different Stages of HIV-1 Disease Relate To Its Progression in Therapy Naïve Individuals. J AIDS Clin Res 4: 207. doi:10.4172/2155-6113.1000207

1) and macrophage tropism are associated with mother-to-infant transmission. $\mathrm{J}$ Infect Dis 180: 344-350.

21. Lee HY, Perelson AS, Park SC, Leitner T (2008) Dynamic correlation between intrahost HIV-1 quasispecies evolution and disease progression. PLoS Comput Biol 4: e1000240.

22. Raymond S, Delobel P, Mavigner M, Cazabat M, Encinas S, et al. (2010) CXCR4-using viruses in plasma and peripheral blood mononuclear cells during primary HIV-1 infection and impact on disease progression. AIDS 24: 23052312.

23. van't Wout $A B$, Kootstra NA, Mulder-Kampinga GA, Albrecht-van Lent $N$ Scherpbier HJ, et al. (1994) Macrophage-tropic variants initiate human immunodeficiency virus type 1 infection after sexual, parenteral, and vertical transmission. J Clin Invest 94: 2060-2067.

24. Wu Y (2009) The co-receptor signaling model of HIV-1 pathogenesis in peripheral CD4 T cells. Retrovirology 6: 41.

25. Giovannetti A, Ensoli F, Mazzetta F, De Cristofaro M, Pierdominici M, et al. (1999) CCR5 and CXCR4 chemokine receptor expression and beta-chemokine production during early $\mathrm{T}$ cell repopulation induced by highly active antiretroviral therapy. Clin Exp Immunol 118: 87-94.

26. Bleul CC, Wu L, Hoxie JA, Springer TA, Mackay CR (1997) The HIV coreceptors CXCR4 and CCR5 are differentially expressed and regulated on human T lymphocytes. Proc Natl Acad Sci U S A 94: 1925-1930.

27. Ostrowski MA, Justement SJ, Catanzaro A, Hallahan CA, Ehler LA, et al. (1998) Expression of chemokine receptors CXCR4 and CCR5 in HIV-1-infected and uninfected individuals. J Immunol 161: 3195-3201.

28. Moore JP, Kitchen SG, Pugach P, Zack JA (2004) The CCR5 and CXCR4 coreceptors--central to understanding the transmission and pathogenesis of human immunodeficiency virus type 1 infection. AIDS Res Hum Retroviruses 20: $111-126$.

29. Cilliers T, Nhlapo J, Coetzer M, Orlovic D, Ketas T, et al. (2003) The CCR5 and CXCR4 coreceptors are both used by human immunodeficiency virus type 1 primary isolates from subtype C. J Virol 77: 4449-4456.

30. Connell BJ, Michler K, Capovilla A, Venter WD, Stevens WS, et al. (2008) Emergence of $\mathrm{X} 4$ usage among HIV-1 subtype C: evidence for an evolving epidemic in South Africa. AIDS 22: 896-899.

31. Johnston ER, Zijenah LS, Mutetwa S, Kantor R, Kittinunvorakoon C, et al. [2003] High frequency of syncytium-inducing and CXCR4-tropic viruses among human immunodeficiency virus type 1 subtype $\mathrm{C}$-infected patients receiving antiretroviral treatment. J Virol 77: 7682-7688.

32. Raymond S, Delobel P, Mavigner M, Ferradini L, Cazabat M, et al. (2010) Prediction of HIV type 1 subtype $C$ tropism by genotypic algorithms built from subtype B viruses. J Acquir Immune Defic Syndr 53: 167-175.

33. Bentwich Z, Kalinkovich A, Weisman Z (1995) Immune activation is a dominant factor in the pathogenesis of African AIDS. Immunol Today 16: 187-191.

34. Bentwich Z, Maartens G, Torten D, Lal AA, Lal RB (2000) Concurrent infections and HIV pathogenesis. AIDS 14: 2071-2081.

35. Fraziano M, Cappelli G, Santucci M, Mariani F, Amicosante M, et al. (1999) Expression of CCR5 is increased in human monocyte-derived macrophages and alveolar macrophages in the course of in vivo and in vitro Mycobacterium tuberculosis infection. AIDS Res Hum Retroviruses 15: 869-874.

36. Djoba Siawaya JF, Ruhwald M, Eugen-Olsen J, Walzl G (2007) Correlates for disease progression and prognosis during concurrent HIV/TB infection. Int J Infect Dis 11: 289-299.
37. Morris L, Martin DJ, Bredell $H$, Nyoka SN, Sacks L, et al. (2003) Human immunodeficiency virus-1 RNA levels and CD4 lymphocyte counts, during treatment for active tuberculosis, in South African patients. J Infect Dis 187 1967-1971.

38. Blaak H, van't Wout AB, Brouwer M, Hooibrink B, Hovenkamp E, et al. (2000) In vivo HIV-1 infection of CD45RA(+)CD4(+) T cells is established primarily by syncytium-inducing variants and correlates with the rate of CD4(+) T cell decline. Proc Natl Acad Sci U S A 97: 1269-1274.

39. Fenyö EM, Morfeldt-Månson L, Chiodi F, Lind B, von Gegerfelt A, et al. (1988) Distinct replicative and cytopathic characteristics of human immunodeficiency virus isolates. J Virol 62: 4414-4419.

40. Karlsson I, Grivel JC, Chen SS, Karlsson A, Albert J, et al. (2005) Differential pathogenesis of primary CCR5-using human immunodeficiency virus type 1 isolates in ex vivo human lymphoid tissue. J Virol 79: 11151-11160.

41. Tersmette M, Gruters RA, de Wolf F, de Goede RE, Lange JM, et al. (1989) Evidence for a role of virulent human immunodeficiency virus (HIV) variants in the pathogenesis of acquired immunodeficiency syndrome: studies on sequential HIV isolates. J Virol 63: 2118-2125.

42. Holmes EC (2001) On the origin and evolution of the human immunodeficiency virus (HIV). Biol Rev Camb Philos Soc 76: 239-254.

43. Bozek K, Thielen A, Sierra S, Kaiser R, Lengauer T (2009) V3 loop sequence space analysis suggests different evolutionary patterns of CCR5- and CXCR4tropic HIV. PLoS One 4: e7387.

44. Bunnik EM, Swenson LC, Edo-Matas D, Huang W, Dong W, et al. (2011) Detection of inferred CCR5- and CXCR4-using HIV-1 variants and evolutionary intermediates using ultra-deep pyrosequencing. PLoS Pathog 7: e1002106.

45. De Jong JJ, De Ronde A, Keulen W, Tersmette M, Goudsmit J (1992) Minimal requirements for the human immunodeficiency virus type $1 \mathrm{~V} 3$ domain to support the syncytium-inducing phenotype: analysis by single amino acid substitution. J Virol 66: 6777-6780.

46. Fouchier RA, Groenink M, Kootstra NA, Tersmette M, Huisman HG, et al. [1992] Phenotype-associated sequence variation in the third variable domain of the human immunodeficiency virus type $1 \mathrm{gp} 120$ molecule. J Virol 66: 3183-3187.

47. Jensen MA, Li FS, van 't Wout AB, Nickle DC, Shriner D, et al. (2003) Improved coreceptor usage prediction and genotypic monitoring of R5-to-X4 transition by motif analysis of human immunodeficiency virus type 1 env $\mathrm{V} 3$ loop sequences. J Virol 77: 13376-13388.

48. Mansky LM, Temin HM (1995) Lower in vivo mutation rate of human immunodeficiency virus type 1 than that predicted from the fidelity of purified reverse transcriptase. J Virol 69: 5087-5094.

49. Pastore C, Ramos A, Mosier DE (2004) Intrinsic obstacles to human immunodeficiency virus type 1 coreceptor switching. J Virol 78: 7565-7574.

50. Perelson AS (2002) Modelling viral and immune system dynamics. Nat Rev Immunol 2: 28-36.

51. Morris L, Cilliers T, Bredell H, Phoswa M, Martin DJ (2001) CCR5 is the major coreceptor used by HIV-1 subtype $C$ isolates from patients with active tuberculosis. AIDS Res Hum Retroviruses 17: 697-701. 